\title{
Preparation and characterization of polystyrene-b-poly(2-vinylpyridine) coordinated to metal or metal ion nanoparticles
}

\author{
Tugba Orhan Lekesiz ${ }^{\mathrm{a}}$, Kadir Kaleli ${ }^{\mathrm{a}}$, Tamer Uyar ${ }^{\mathrm{b}}$, Ceyhan Kayran ${ }^{\mathrm{a}}$, Jale Hacaloglu ${ }^{\mathrm{a}, *}$ \\ a Middle East Technical University, Chemistry Department, TR-06800 Ankara, Turkey \\ ${ }^{\mathrm{b}}$ Bilkent Univ, UNAM Inst Mat Sci \& Nanotechnol, TR-06800 Ankara, Turkey
}

\section{A R T I C L E I N F O}

\section{Article history:}

Received 15 March 2013

Accepted 1 January 2014

Available online 9 January 2014

\section{Keywords:}

Metal or metal ion nanoparticles,

Polystyrene-block-poly(2-vinylpyridine)

Thermal degradation

Pyrolysis mass spectrometry

\begin{abstract}
A B S T R A C T
In this study, $\mathrm{Co}, \mathrm{Cr}$ or $\mathrm{Au}^{3+}$ functional polystyrene-block-poly(2-vinylpyridine), PS-b-P2VP complexes were prepared and characterized. Coordination of metal atom or ion to nitrogen atom of pyridine rings was confirmed by FTIR analyses. The strength and efficiency of coordination of P2VP blocks to $\mathrm{Co}, \mathrm{Cr}$ or $\mathrm{Au}^{3+}$ mainly depends on charge and stability of the complex formed that is mainly related to the energy of $d$ orbitals. The results reveal that the thermal stability of the polymer composite formed increases with the increase in strength of the coordination. Changes in thermal decomposition mechanism and product distribution were recorded. Degradation of P2VP units coordinated to $\mathrm{Cr}$, $\mathrm{Co}$ or $\mathrm{Au}^{3+}$ was started by loss of pyridine units leaving an unsaturated and/or crosslinked polymer backbone that degraded at relatively high temperatures.
\end{abstract}

(C) 2014 Elsevier B.V. All rights reserved.

\section{Introduction}

Nanostructures have received great attention recently due to their special optical, electronic, magnetic and chemical properties [1-5]. The most popular approach involves the synthesis of nanoparticles in situ within the block copolymer template by using preformed micelles of block copolymers containing metal precursors [6-11]. As a consequence of the strong affinity of the amines to various ions and polar groups, the polymers containing a pyridine moiety can make strong bonds with various metal ions or nanoparticles and have attracted increasing attention.

In recent studies, poly(vinylpyridine) (PVP) was widely used to synthesize nanoparticles by itself as well as in combination with other polymers. Block copolymers with the ability to form stable micelles in solution and at interfaces are excellent candidates for the preparation of various metal nanoparticles with a narrow size distribution and long-term stability [12-17].

For example, Moeller et al. $[15,16]$ has prepared gold nanoparticles with the use of polystyrene-block-poly-2-vinylpyridine (PS-b-P2VP) copolymer for the first time. The metal salts formed complexes with the pendant pyridine rings, concentrating the metal ions in the poly-2-vinylpyridine domains. Lohmueller et al.

\footnotetext{
* Corresponding author. Tel.: +90 312210 5148; fax: +90 3122103200

E-mail address: jale@metu.edu.tr (J. Hacaloglu).
}

[17] fabricated various metal nanoparticles ( $\mathrm{Au}, \mathrm{Pt}$, and $\mathrm{Pd}$ ) packed in quasi-hexagonal ordering using PS-b-P2VP micelles. The size of nanoparticles was controlled by the immersion time into a solution containing metal precursors.

Coordination of metal/metal ion improves the thermal stability of the host polymer [18-22]. Zander et al. [22], studied the thermal characterization of poly(4-vinylpyridine) crosslinked with metal salts and suggested that Tg enhancement was highly dependent upon the type and loading of the metal salt. Wu et al. [21] investigated $\mathrm{Tg}$ value of poly(4-vinylpyridine) copolymer and its complex with transition metal ion and determined that $\mathrm{Tg}$ increases with increasing the metal ions content. The result reveals that upon coordination of the pyridine rings to the metal ions the intermolecular interactions are enhanced.

However, the knowledge of thermal characteristics and degradation mechanisms of these composites that are very important for investigation of application areas is still limited. Among the several thermal analysis methods, direct pyrolysis mass spectrometry (DP-MS) is the only one that gives information on not only thermal stability but also on primary and unstable thermal degradation products that are very important for investigation of thermal degradation mechanism [23].

In the present study, thermal characterization of polystyreneblock-poly(2vinyl pyridine), PS-b-P2VP, coordinated to $\mathrm{Co}, \mathrm{Cr}$ and $\mathrm{Au}^{3+}$ nanoparticles were investigated via DP-MS technique to elucidate the effect of metal coordination on thermal stability and degradation mechanism. 


\section{Experimental}

\subsection{Materials and synthesis}

PS-b-P2VP was purchased from Polymer Source Inc. (PS: $\mathrm{Mn}=25,000$, P2VP: $\mathrm{Mn}=15,000, \mathrm{PDI}=1.04) . \mathrm{Co}_{2}(\mathrm{CO})_{8}$ and $\mathrm{Cr}(\mathrm{CO})_{6}$ were purchased from Aldrich Chemical Company and $\mathrm{HAuCl}_{4} \cdot 3 \mathrm{H}_{2} \mathrm{O}$ was purchased from Acros Organics and used without further purification. Toluene, purchased from Aldrich, was purified by refluxing over metallic sodium under nitrogen for two or three days.

Metal functional PMMA-b-P2VP polymers were prepared according to the literature methods [24]. As a summary, the polymer was dissolved in toluene by stirring overnight to form micelles. After the dissolution of the polymer, the metal or metal ion complexes, keeping the number of moles of metal or metal ion equal to that of 2 VP repeating units, were added to this solution and refluxed for $8 \mathrm{~h}$. After evaporation of the solvent under vacuum, the resultant product was analyzed by TEM, FTIR and DP-MS techniques. Among the several metals and metal ions tested nanoparticles could only be obtained for $\mathrm{Co}, \mathrm{Cr}$ and $\mathrm{Au}^{3+}$.

\subsection{Instrumentation}

FTIR analyses of the samples were performed by Bruker Vertex 70 Spectrophotometer.

TEM imaging of the nanoparticles was carried out with a Tecnai G2 F30 instrument at $200 \mathrm{kV}$ (UNAM - BILKENT University). The nanoparticles were dispersed on the carbon-coated copper grid from their diluted suspension in toluene.

Thermogravimetry analyses (TGA and DTA) were conducted on Perkin Elmer Pyris 1 TGA equipment, heating at $10^{\circ} \mathrm{C} \mathrm{min}^{-1}$ under nitrogen atmosphere from ambient temperature to $600^{\circ} \mathrm{C}$.

Direct pyrolysis mass spectrometry, DP-MS, analyses were performed by a triple quadruple Waters Micromass Quattro Micro GC Mass Spectrometer with a mass range of 10-1500 Da coupled to a direct insertion probe. During the pyrolysis, the temperature was increased to $50^{\circ} \mathrm{C}$ at a rate of $5^{\circ} \mathrm{C} \mathrm{min}^{-1}$, then, was raised to $650^{\circ} \mathrm{C}$ with a rate of $10^{\circ} \mathrm{C} \mathrm{min}^{-1}$ and kept at $650^{\circ} \mathrm{C}$ for 5 additional minutes. $0.01 \mathrm{mg}$ samples were pyrolyzed in the flared quartz sample vials while recording $70 \mathrm{eV}$ EI mass spectra at a mass scan rate of 1 scan s$^{-1}$. The analyses were repeated several times to ensure reproducibility. Each time, almost exactly the same trends were detected.

\section{Results and discussion}

The TEM images of the metal-functional polymers, Cr-PS-bP2VP, Co-PS-b-P2VP, Au-PS-b-P2VP, shown in Fig. 1, pointed out well dispersed metal or metal ion nanoparticles in the PS-b-P2VP matrix. The size of $\mathrm{Cr}$ and $\mathrm{Co}$ nanoparticles were comparable, while

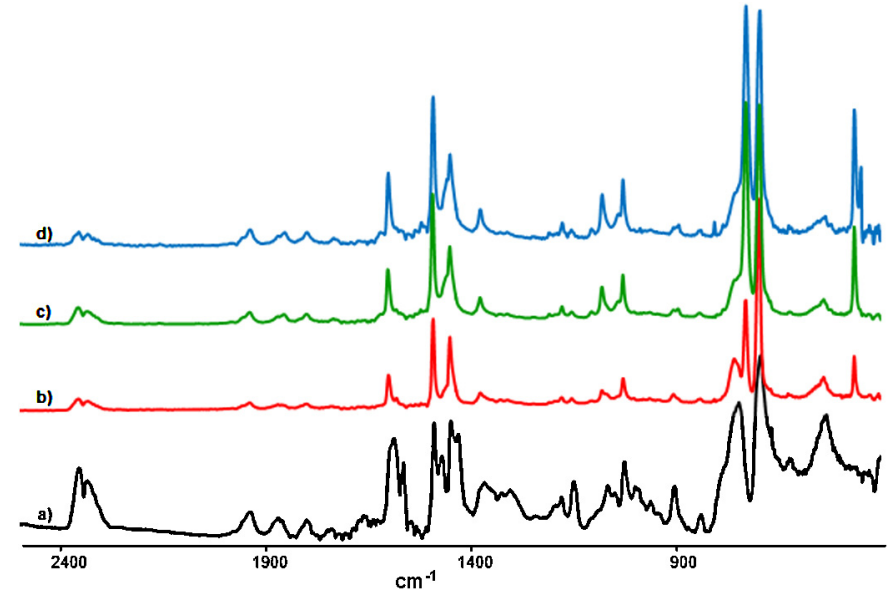

Fig. 2. FTIR spectra of (a) PS-b-P2VP, (b) Co, (c) $\mathrm{Cr}$ and (d) $\mathrm{Au}^{3+}$ functional PS-b-P2VP.

$\mathrm{Au}(\mathrm{III})$ nanoparticles were about more than 2-folds smaller. Furthermore, the images indicated that coordination to $\mathrm{Au}^{3+}$ was significantly more efficient. On the other, the extent of coordination to $\mathrm{Cr}$ seemed to be not very productive.

As the nanoparticle formation starts by the coordination of the electron-rich segment of the copolymer, 2-vinylpyridine, to the metal atom or ion by the exclusion of the ligands, the pyridine stretching and bending modes of pyridine ring are affected.

For Co and $\mathrm{Cr}$ functional PS-b-P2VP, the displacement of CO ligands by pyridines was confirmed by the disappearance of the peaks associated with carbonyl groups of $\mathrm{Co}_{2}(\mathrm{CO})_{8}(2023,2041$, $2071 \mathrm{~cm}^{-1}$ ) and $\mathrm{Cr}(\mathrm{CO})_{6}$ (at around $2000 \mathrm{~cm}^{-1}$ ) completely. The relative intensities of the absorption peaks due to the pyridine strecthing and bending modes in the range of $1590-600 \mathrm{~cm}^{-1}$, especially the ones at around $1590 \mathrm{~cm}^{-1} 1472$ and $1431 \mathrm{~cm}^{-1}$ were decreased significantly in all these complexes. Characteristic uncoordinated pyridine ring vibration at around $1590 \mathrm{~cm}^{-1}$ shifted to $1604 \mathrm{~cm}^{-1}$ for $\mathrm{Co}$ and $\mathrm{Au}^{3+}$ functional copolymers and to $1602 \mathrm{~cm}^{-1}$ $\mathrm{Cr}$ coordinated rings. A new absorption peak appeared at around $464 \mathrm{~cm}^{-1}$ detected for all the composites was associated with $\mathrm{N}$ metal stretching mode (Fig. 2). Considering the relative intensities of the peaks associated with $\mathrm{N}$-metal stretching normalized with respect to the peaks due to phenyl ring vibrations it can be concluded that extent of coordination was comparable for $\mathrm{Co}$ and $\mathrm{Au}^{3+}$ whereas not very fruitful for $\mathrm{Cr}$ in accordance with TEM results.

Pyrolysis of the metal and/or metal ion functional copolymers yielded almost identical thermal degradation products. Yet, inspection of pyrolysis mass spectra and single ion evolution profiles pointed out drastic changes in the relative intensities of P2VP based products, especially those associated with protonated oligomers of vinylpyridine, upon coordination to metal or metal ion. a)

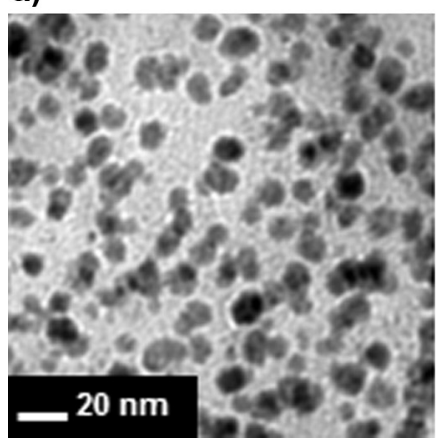

b)

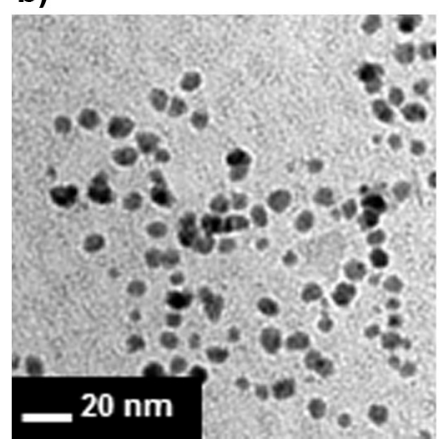

c)

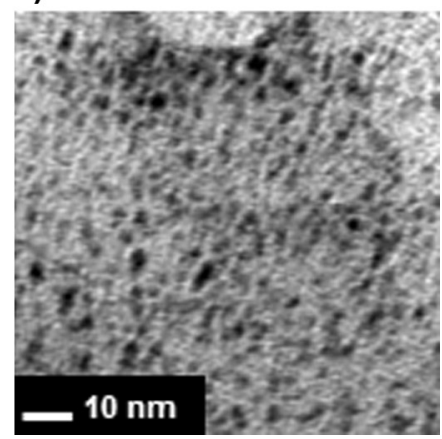

Fig. 1. TEM Images of (a) Co-PS-b-P2VP, (b) Cr-PS-b-P2VP and (c) Au-PS-b-P2VP. 

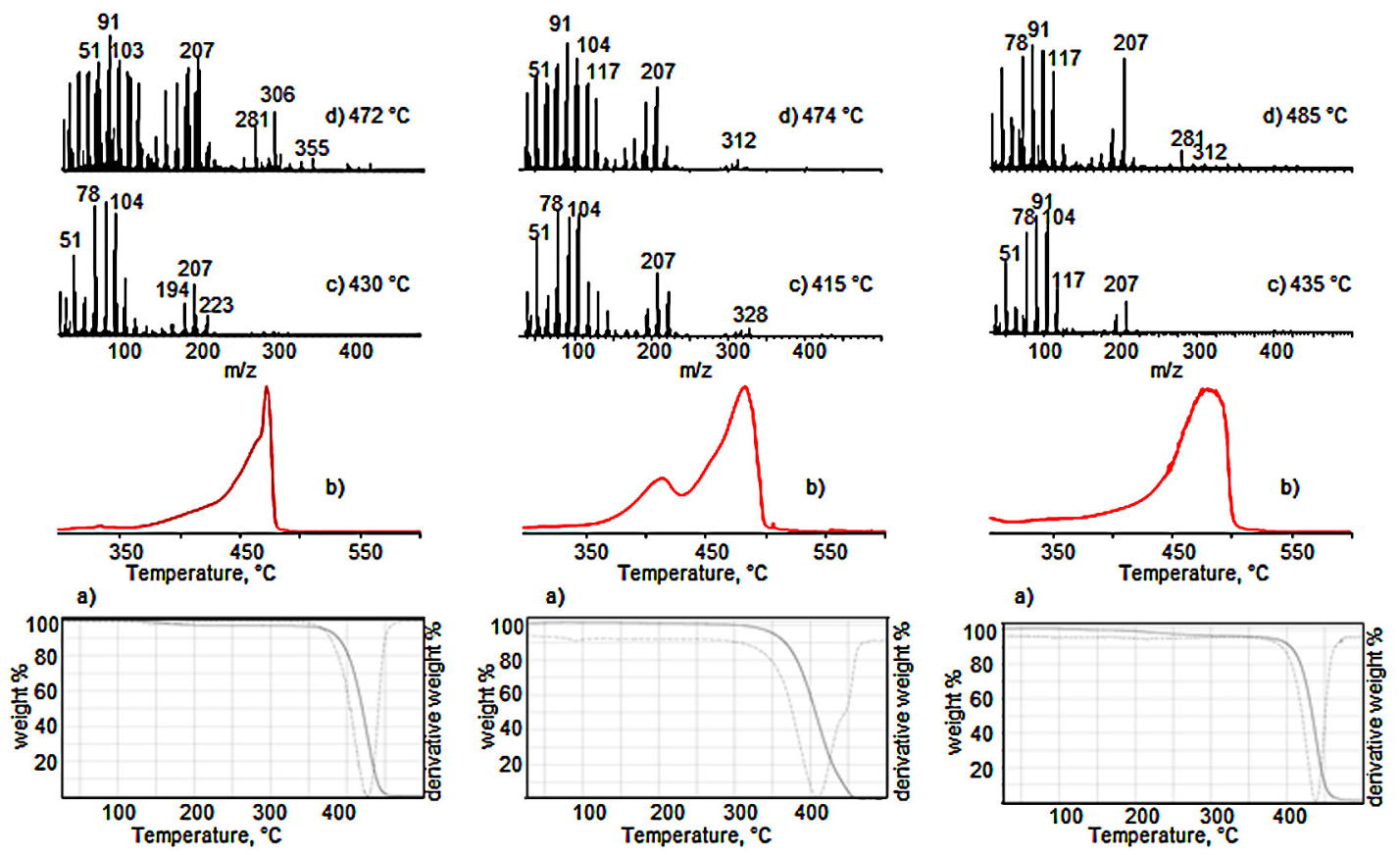

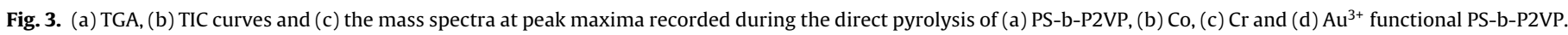

Furthermore, new peaks appeared in the pyrolysis mass spectra at elevated temperatures.

Thermal decomposition mechanisms of polystyrene, PS, and poly(2-vinylpyridine), P2VP, have been studied extensively [25-27]. PS degrades in a single step by a depolymerization reaction to yield mainly, the monomer, styrene $[25,26]$. P2VP decomposes by a complex degradation mechanism producing also protonated oligomers in addition to monomer and low mass oligomers [27]. Previous DP-MS studies revealed that during the pyrolysis of PS-bP2VP copolymer, each component decomposes independently via the decomposition pathways identified for the corresponding pure homopolymers as expected for a block copolymer [28,29].

In Fig. 3 the TGA curves, total ion current (TIC) curves, the variation of total ion yield as a function of temperature, and the pyrolysis mass spectra recorded at peak maxima for of $\mathrm{Co}, \mathrm{Cr}$ and $\mathrm{Au}^{3+}$ functional PS-b-P2VP are presented. In general, the trends in the TGA curves were in accordance with those in TIC curves. In Fig. 4, single ion evolution profiles of $\mathrm{C}_{7} \mathrm{H}_{7}$ (91), St monomer (104), [ $\mathrm{St}_{2}-$ $\mathrm{H}]$ (207) and St dimer (208) that were diagnostic to PS block and $\mathrm{C}_{5} \mathrm{H}_{5} \mathrm{~N}$ (79), 2VP monomer (105), 2VP dimer (210) and 2VP protonated dimer (211) that were characteristic for P2VP block recorded during the pyrolysis of $\mathrm{Co}, \mathrm{Cr}$ and $\mathrm{Au}^{3+}$ functional PS-b-P2VP are shown.

During the pyrolysis of the PS-b-P2VP, VP oligomers and protonated oligomers reached to maximum yield at around 415 and $426^{\circ} \mathrm{C}$ respectively, whereas, PS based products maximized at around $437^{\circ} \mathrm{C}$. The evolution profiles of the thermal degradation products detected during the pyrolysis of PS-b-P2VP are included in Fig. 3 for comparison.

In general, upon coordination to $\mathrm{Co}, \mathrm{Cr}$ or $\mathrm{Au}^{3+}$, the evolution profiles of P2VP based products showed overlapping peaks indicating presence of P2VP chains with noticeably different thermal stabilities. The low temperature peaks with a maximum at 417,405 and $395^{\circ} \mathrm{C}$ in the evolution profiles of P2VP based products for Co, $\mathrm{Cr}$ or $\mathrm{Au}^{3+}$ functional copolymers respectively, can be attributed to degradation of unreacted 2VP segments (Fig. 4b-d). On the other hand, the corresponding high temperature peaks at 472,474 and $485^{\circ} \mathrm{C}$ can be associated with decomposition of vinyl pyridine units coordinated to metals or metal ion. The loss of pyridine and vinyl pyridine was noticeably suppressed in the low temperature region. An opposite trend was detected for the oligomers and protonated oligomers. They were mainly eliminated at initial stages of pyrolysis. In addition, the relative yields of these products decreased significantly. It may be thought that upon coordination to metal or metal ion the extent of 2VP segments of two or more repeating units involving uncoordinated pyridine rings was quite low. Actually, the decrease in the relative intensities was more pronounced for the protonated oligomers. Thus, it may further be thought that upon coordination of pyridine nitrogen to $\mathrm{Co}, \mathrm{Cr}$ or $\mathrm{Au}^{3+}$, the probability of generation of protonated oligomers by $\mathrm{H}$-transfer to $\mathrm{N}$ atom decreased significantly [29].

The broad peaks present in the single ion pyrograms of thermal degradation products of PS shifted to high temperature regions. Maximum yields for PS based products were detected at 472, 474 and $485^{\circ} \mathrm{C}$ for $\mathrm{Co}, \mathrm{Cr}$ or $\mathrm{Au}^{3+}$ functional copolymers respectively. Shoulders in the temperature regions where PS decomposition occurs for the virgin copolymer were detected.

Product peaks which were either totally absent or only very weak in the pyrolysis mass spectra of the copolymer, at $\mathrm{m} / \mathrm{z}$ values $267,281,306,325,355,429,461,613$, etc. were noticeably intense, except for $\mathrm{Cr}$ functional sample. The single ion evolution profiles of products with $m / z$ values 281 and 355 attributed to $\mathrm{C}_{23} \mathrm{H}_{29}$ and $\mathrm{C}_{29} \mathrm{H}_{31}$ are also included in Fig. 4. The evolution profiles of these products showed identical trends, a sharp peak with a maximum at 472 and $499{ }^{\circ} \mathrm{C}$ for $\mathrm{Co}$ and $\mathrm{Au}^{3+}$ functional P-b-P2VP respectively. In case of $\mathrm{Cr}$ functional copolymer the yields of these products were quite low. In addition they were eliminated in a broad temperature region.

It may be thought that due to the strong interaction between metal atoms/ions and the nitrogen atom on the pyridine rings, the mass of the pyridine rings increases affecting the thermal degradation of P2VP block. The high temperature peaks or shoulders present in the evolution profiles of P2VP based products supported this proposal. A degradation mechanism involving loss of side 


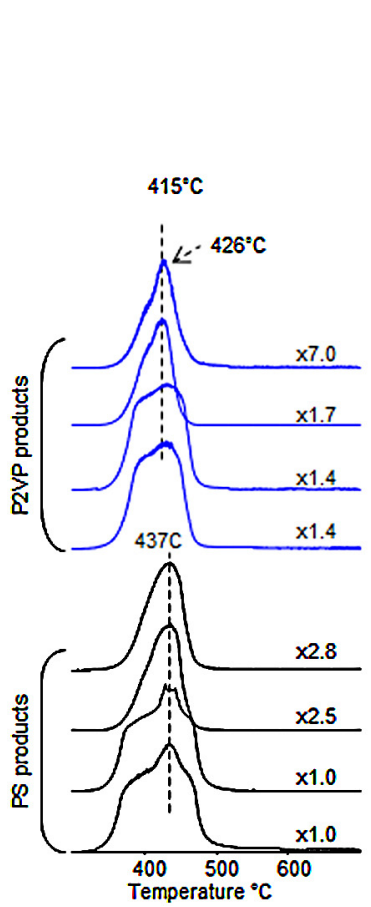

b) Co-PS-b-P2VP

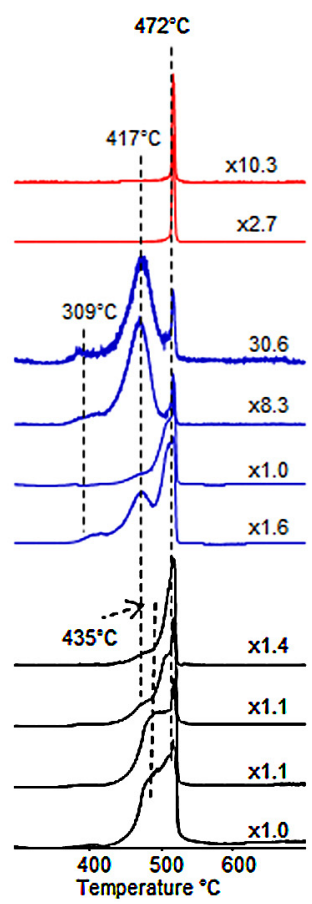

c) Cr-PS-b-P2VP

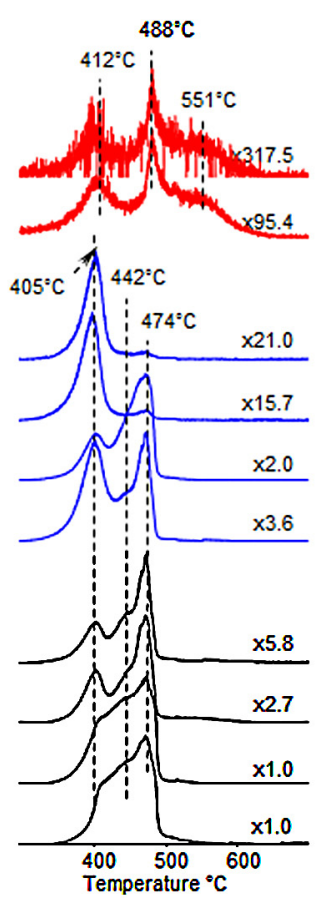

d) $A u^{30}-P S-b-P 2 V P$

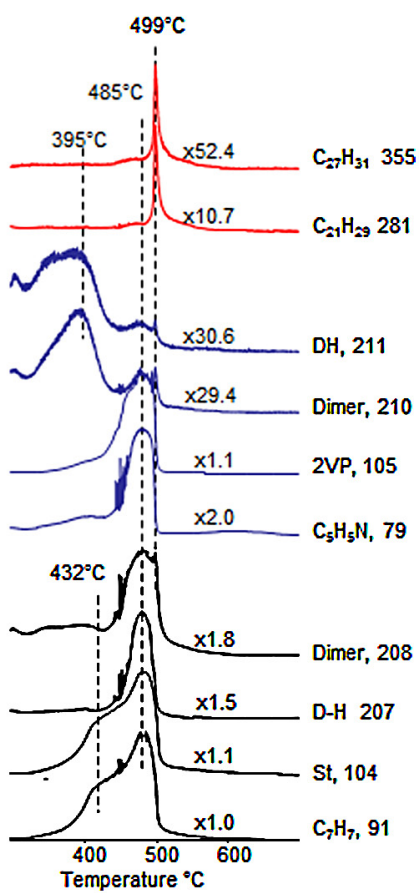

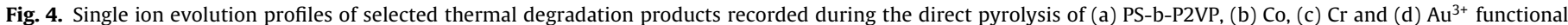
PS-b-P2VP.

chains in the first step can be suggested to be preferential compared to the depolymerization mechanism (Scheme 1). Upon loss of pyridine rings, intermolecular coupling reactions may take place yielding either conjugated double bonds or crosslinked structures that decompose at relatively high temperatures.

The detection of new products at elevated temperature that can readily be associated with hydrocarbon units involving $\mathrm{H}$ deficiency was in accordance with the expectations. As a consequence, the sharp high temperature peaks present in the evolution profiles of characteristic thermal decomposition products of P2VP and PS may then be attributed with contribution of products due to the degradation of these unsaturated chains or crosslinked structures with the same $m / z$ values.

The trends in the evolution profiles of diagnostic thermal degradation products of P2VP, PS and the new unsaturated units for the

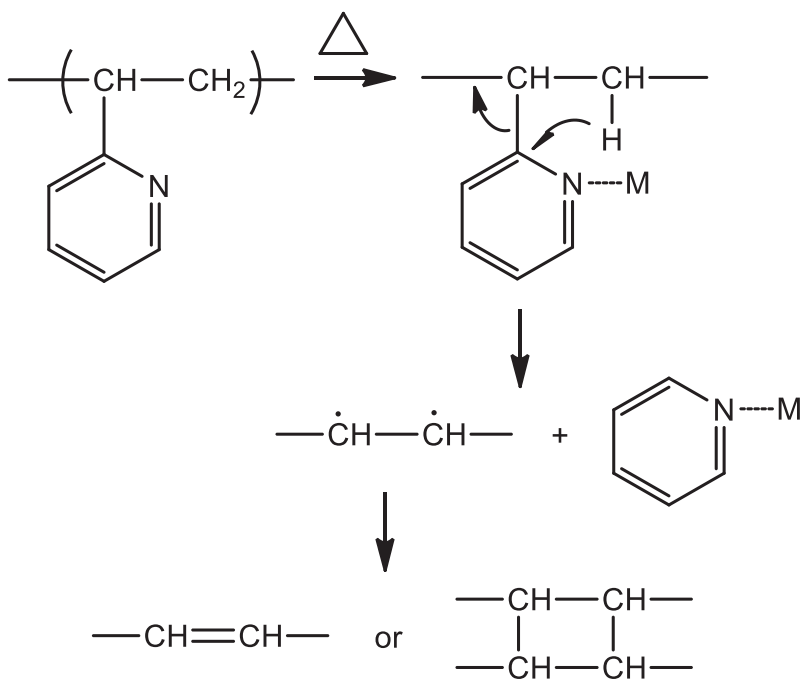

Scheme 1. Thermal decomposition of metal-functional P2VP chains. composites involving $\mathrm{Co}$ or $\mathrm{Au}^{3+}$ coordination was quite similar. The only difference was the increase in thermal stability in the presence of $\mathrm{Au}^{3+}$ that may be associated with the higher molar mass of Au. Furthermore, the noticeable decrease in the relative intensities of thermal degradation products of unreacted P2VP noted for this sample can be related to a stronger interaction between the $\mathrm{N}$ of pyridine rings due to the high positive charge of $\mathrm{Au}^{3+}$ ion.

For the $\mathrm{Cr}$ coordinated composite, the relative yields of thermal degradation products of unreacted P2VP are higher whereas those of unsaturated hydrocarbon units are remarkably lower than the corresponding ones for $\mathrm{Co}$ and $\mathrm{Au}^{3+}$ analogues, in accordance with the TEM results. Furthermore, three overlapping peaks were present in the evolution profiles of unsaturated hydrocarbon units, instead of the sharp peak recorded for $\mathrm{Co}$ and $\mathrm{Au}^{3+}$ coordinated PS-b-P2VP. The smallest effective nuclear charge of $\mathrm{Cr}$ may be regarded as one of the possible sources for the weakest interaction with pyridine. In addition, one should also consider the degeneracy of the energy levels of $\mathrm{Co}, \mathrm{Cr}$ and $\mathrm{Au}^{3+}$ used for coordination. The square planar $\mathrm{Au}^{3+}$ complex and Co complex as a result of tetragonal distortion, have similar type of $d$ orbital splitting. Having non-degenerate $d$ orbitals, the energy of the complexes formed decreased. It may be thought that, as a consequence, the possibility of $\pi$-back bonding between pyridine and $\mathrm{Co}$ and $\mathrm{Au}^{3+}$ increases, yielding a stronger coordination. On the other, such a distortion that stabilizes the complex formed is not expected for $\mathrm{Cr}$ complex. Furthermore, both low and high spin configurations, affecting the strength of coordination may also be considered for this complex, as for a $\mathrm{d}^{6}$ metal complex spin crossover initiated by a change in pressure or temperature sometimes occurs.

\section{Conclusion}

In the present study, it has been determined that the strength and efficiency of coordination of P2VP blocks to $\mathrm{Co}, \mathrm{Cr}$ or $\mathrm{Au}^{3+}$ mainly depends on charge and stability of the complex formed that is mainly related to the energy of $d$ orbitals. The results reveal that 
the thermal stability of the polymer composite formed increases with the increase in strength of coordination.

\section{Acknowledgment}

This work is partially supported by TUBITAK Research Funds TBAG-106T092 and TBAG-106T656.

\section{References}

[1] N.L. Pocard, D.C. Alsmeyer, R.L. McCreery, T.X. Neenan, M.R. Callstrom, Nanoscale platinum (0) clusters in glassy-carbon - synthesis, characterization, and uncommon catalytic activity, J. Am. Chem. Soc. 114 (1992) 769-771.

[2] W.L. Barnes, A. Dereux, T.W. Ebbesen, Surface plasmon subwavelength optics, Nature 424 (2003) 824-830.

[3] T.K. Sau, A.L. Rogach, F. Jackel, T.A. Klar, J. Feldmann, Properties and applications of colloidal nonspherical noble metal nanoparticles, Adv. Mater. 22 (2010) $1805-1825$

[4] P.K. Jain, X.H. Huang, I.H. El-Sayed, M.A. El-Sayed, Noble metals on the nanoscale: optical and photothermal properties and some applications in imaging, sensing, biology, and medicine, Acc. Chem. Res. 41 (2008) 1578-1586.

[5] D.L. Lesliepelecky, R.D. Rieke, Magnetic properties of nanostructured materials, Chem. Mater. 8 (1996) 1770-1783.

[6] M.R. Bockstaller, R.A. Mickiewicz, E.L. Thomas, Block copolymer nanocomposites: perspectives for tailored functional materials, Adv. Mater. 17 (2005) $1331-1349$

[7] S.B. Darling, Directing the self-assembly of block copolymers, Prog. Polym. Sci. 32 (2007) 1152-1204.

[8] J.K. Kim, S.Y. Yang, Y. Lee, Y. Kim, Functional nanomaterials based on block copolymer self-assembly, Prog. Polym. Sci. 35 (2010) 1325-1349.

[9] S.I. Yoo, J.H. Kwon, B.H. Sohn, Single layers of diblock copolymer micelles for the fabrication of arrays of nanoparticles, J. Mater. Chem. 17 (2007) 2675-2969.

[10] H. Cho, H. Park, T.P. Russell, S. Park, Precise placements of metal nanoparticles from reversible block copolymer nanostructures, J. Mater. Chem. 20 (2010) 5047-5051.

[11] S. Papp, L. Korosi, B. Gool, T. Dederichs, P. Mela, M. Moller, I. Dekany, Formation of gold nanoparticles in diblock copolymer micelles with various reducing agents, J. Therm. Anal. Calorim. 101 (2010) 865-872.

[12] J.P. Spatz, S. Mossmer, C. Hartmann, M. Mooller, T. Herzog, M. Krieger, H.G Boyen, P.Ziemann, Ordered deposition of inorganic clusters from micellar block copolymer films, Langmuir 16 (2000) 407-415.
[13] R. Suntivich, I. Choi, M.K. Gupta, C. Tsitsilianis, V. Tsukruk, Gold nanoparticles grown on star-shaped block copolymer monolayers, Langmuir 27 (2011) 10730-10738.

[14] J--H. Kim, S.H. Bae, S. Chae, B.-H. Sohn, Inversion of diblock copolymer micelles by selective solvents for conversion of gold nanopatterns, Thin Solid Films 520 (2012) 2022-2025

[15] R. Glass, M. Moeller, J.P. Spatz, Block copolymer micelle nanolithography, Nanotechnology 14 (2003) 1153-1160.

[16] M. Moeller, J.P. Spatz, Mineralization of nanoparticles in block copolymer micelles, Curr. Opin. Colloids Interface Sci. 2 (1997) 177-187.

[17] T. Lohmueller, E. Bock, J.P. Spatz, Synthesis of quasi-hexagonal ordered arrays of metallic nanoparticles with tuneable particle size, Adv. Mater. 20 (2008) 2297-2302.

[18] J.H. Cho, J.K. Hong, K. Char, F. Caruso, Nanoporous block copolyme micelle/micelle multilayer films with dual optical properties, J. Am. Chem. Soc 128 (2006) 9935-9942.

[19] K.S. Khairou, M.A. Diab, Stability and degradation of poly(4-vinylpyridine) and copolymers of 4-vinylpyridine with methyl-methacrylate, Polym. Degrad. Stab. 44 (1994) 17-20.

[20] A.M. Lyons, E.M. Pearce, A.M. Mujsce, Thermal-decomposition of poly(2vinylpyridine) - effect of complexation with copper chloride, J. Polym. Sci. A Polym. Chem. 28 (1990) 245-259

[21] K.H. Wu, Y.R. Wang, W.H. Hwu, FTIR and TGA studies of poly(4-vinylpyridineco-divinylbenzene)-Cu(II) complex, Polym. Degrad. Stab. 79 (2003) 195-200.

[22] N.E. Zander, J.A. Orlicki, A.M. Rawlett, Weapons and Materials Research Directorate, ARL.

[23] J. Hacaloglu, Direct insertion probe mass spectrometry of polymers, Adv. Polym. Sci. 248 (2012) 69-103.

[24] V.V. Baranauskas, M.A. Zalich, M. Saunders, T.G. St Pierre, J.S. Riffle, Poly(styrene-b-4-vinylphenoxyphthalonitrile) - cobalt complexes and their conversion to oxidatively stable cobalt nanoparticles, Chem. Mater. 17 (2005) 5246-5254.

[25] I.C. McNeil, M. Zulfiqar, T. Kousar, A detailed investigation of the products of the thermal-degradation of polystyrene, Polym. Degrad. Stab. 28 (1990) 131-151 (and references cited therein).

[26] Y. Nur, S. Yurteri, I. Cianga, Y. Yagci, J. Hacaloglu, Pyrolysis of polyphenylenes with PCL or/and PSt side chains, J. Anal. Appl. Pyrol. 80 (2007) 453-459.

[27] A. Elmaci, J. Hacaloglu, Thermal degradation of poly(vinylpyridine)s, Polym. Degrad. Stab. 94 (2009) 738-743.

[28] T. Orhan, J. Hacaloglu, Thermal degradation of poly(2-vinylpyridine) copolymers, Polym. Degrad. Stab. 98 (2013) 356-360.

[29] A. Elmaci, J. Hacaloglu, C. Kayran, G. Sakellariou, N. Hadjichristidis, Thermal decomposition of polystyrene-b-poly(2-vinylpyridine) coordinated to co nanoparticles, Polym. Degrad. Stab. 94 (2009) 2023-2027 